\title{
ETHICAL APPROACH TO PREVENTION OF SCHIZOPHRENIA - CONCEPTS AND CHALLENGES
}

\author{
Kresimir Radic $^{1}$, Marko Curkovic ${ }^{1}$, Dario Bagaric ${ }^{2}$, Maja Vilibic ${ }^{3}$, Andrea Tomic ${ }^{1}$ \& Maja Zivkovic ${ }^{1}$ \\ ${ }^{1}$ University Psychiatric Hospital Vrapče, Zagreb, Croatia \\ ${ }^{2}$ Graduate Entry Medical School, University of Limerick, Ireland \\ ${ }^{3}$ University Hospital Center "Sisters of Mercy", Zagreb, Croatia
}

received: 16.1.2017;

revised: 12.10.2017;

accepted: 29.12 .2017

\section{SUMMARY}

Patients with schizophrenia, nowadays chronic, frequently disabling mental disorder, get initial treatment after detection of a psychotic episode, seemingly late, potentially preventable stage of illness. As our knowledge about the nature of schizophrenia and other diseases of the spectrum is growing, so are the early interventions becoming more possible, and it is important to conceptualize the clinical, legal and moral issues emerging with new preventive treatments. Every intervention, especially in pre-clinical population, demands a careful risk-benefit assessment and having basic bioethical principles - primacy of patient's welfare, beneficience/non-maleficience, autonomy and justice - in mind. We believe that pharmacological treatments, considering today's drugs safety and effectiveness profiles, should stay reserved for cases with higly probable negative outcomes to patient's wellbeing, and that all other low-risk interventions, like psychosocial treatments, should be considered for reducing the conversion to disorder, if possible, or relieving the distress in vulnerable persons, when such vulnerability gets detected. How to recognize persons at risk before the start of the disorder, without missing the majority of cases or burdening healthy persons with stigma, is another challenge and not only mental health professionals should be included in finding the solutions. The broadest public, and especially the experts that will build the safety-net for the at-risk individuals, should get best possible appropriate education about the schizophrenia in order to stigmatize less and help more.

Key words: ethics - medical - early diagnosis - family health - genetic predisposition to disease - risk factors - primary prevention - schizophrenia - prevention \& control

\section{INTRODUCTION}

After considering a great number of neurobiological, clinical, genetic and epidemiological research findings, biological psychiatrists can now agree schizophrenia is a neurodevelopmental disorder, with genetic and (prenatal and later) environmental factors playing a significant role in its etiopathogenesis. Its highly variable course and clinical phenomenology, an outward of aberrant CNS structures, is a result of nonlinear interactions of genetic factors among themselves and with multiple and various environmental factors, all with variable timing, duration, and severity (Maric \& Svrakic 2012). Patients with this nowadays chronic, frequently disabling mental disorder get initial treatment after detection of a psychotic episode, seemingly late, potentially preventable stage of the illness (Insel 2010, Jakovljevic 2011, Haller et al. 2014).

A number of studies highlighted cognitive decline as a detectable core feature of schizophrenia, with psychosis happening in the later stages of development (Kahn \& Keefe 2013, Keshavan et al. 2010), so the new high aim was set: initiating treatment as early as possible, even prior to the emergence of positive symptoms, including hallucinations and delusions, in order to have patients' long-term functioning remediated and maintained (Cornblatt et al. 2012). In addition to treatment, prevention might become a crucial way to reduce the public health and high-emotional burden of schizophrenia. It seems primary prevention could be a feasible strategy in tackling depression (Cuijpers et al. 2008), but some additional issues arise when considering actions for preventing the onset of schizophrenia, one of the leading causes of long term disability worldwide (Muesser \& McGurk 2004, Vos et al. 2015). In essence, addressing the schizophrenia risk properly and developing evidence-based targets for primary prevention of schizophrenia are crucial and somewhat specific issues that need to be considered, together with the ethical questions they raise.

\section{GENETIC SCREENING: AN EARLY OMEN OR A PROMISE?}

In 1962, American Psychological Association's president Paul Meehl coined the term 'schizotaxia', a genetic predisposition to schizophrenia, or rather "an integrative deficit predisposing to schizophrenia, and of genetic origin" (Meehl 1989). Originally a heretical model, following findings that about 8-15 percent of children with parent with schizophrenia would develop the disorder themselves (Jablensky 2010, ErlenmeyerKimling et al. 1995, Niemi et al. 2004, Parnas et al. 1993) - a rate that is about ten times greater than estimated occurrence of schizophrenia in general population - schizotaxia idea is largely explored, today 
conceptualised with multifactorial polygenic etiology (Tsuang et al. 2002) in interaction with environmental influences throughout a person's lifetime (Nelson et al. 2013), manifesting itself with neuro-psychological, social and symptomatic impairments from the early age (Cornblat et al. 2012, Seidan \& Nordentoft 2015). Since a various degree of decompensation, in relation to the levels of expression of a proposed disease process, is to be expected in vulnerable person, shizotaxia is seen as a quasi-dimensional concept (Nelson et al. 2013), and studies have shown that psychotic symptoms in firstdegree schizophrenia relatives are associated not only with schizophrenia, but with other disorders of a schizophrenia spectrum risk as well (Onstad et al. 1991) and that non-psychotic relatives of schizophrenia patients have observable schizotypal, "schizophrenialike" traits at higher rates than in healthy comparison subjects (Kendler \& Gardner 1997).

Once the phenomenology before the diagnosis of the disorder became the focus of the researchers, somewhat confusing or overlapping terminology for the risk groups emerged, so the exhaustive explanations for underlying concepts and criteria should be looked up (SchultzeLutter et al. 2011). In short, genetically vulnerable persons initially show unspecific complaints and symptoms, then somewhat predictive basic symptoms: subtle, subclinical self-experienced disturbances in thought, speech, and perception processes that are rarely perceivable from outside. Next, some detectable (attenuated, limited) psychotic symptoms can be spotted in fraction of the cases, before the first psychotic episode (Schultze-Lutter 2010). Ultra-high or high clinical risk criteria vary between research groups and mark the imminent conversion to psychosis. That said, models for detecting persons at high clinical risk have emerged, and they feature the genetic component of the risk, various symptoms, social impairment and drug use as baseline predictors (Cannon et al. 2008).

Considering that even when the prediction is applied in the persons with inconclusive symptoms seeking treatment, identified as ones at ultra-high risk, the conversion to psychosis happens in some 30-40 percent of cases (Cornblatt et al. 2012, Fusar-Poli et al. 2012), and knowing that a majority of cases of schizophrenia has no clear family history, it is obvious that designating risk is a practical, and therefore an ethical challenge (McGlashan et al. 2001).

So, in order to predict the persons at risk before the start of the disorder, without missing the majority of cases or burdening healthy family members with stigma, one day genetic analysis might be considered as necessary. But genetic screening for any clinical purpose should be tied to the availability of empirically verified intervention, proposes American College of Obstetricians and Gynecologists (2008). American Society of Human Genetics Board of Directors and American College of Medical Genetics Board of Directors state (in 1995): "If the medical or psychosocial benefits of a genetic test will not accrue until adulthood, as in the case of carrier status or adult-onset diseases, genetic testing generally should be deferred. Exceptions to this principle might occur when the adolescent meets conditions of competence, voluntariness, and adequate understanding of information."

A thoughtful assessment of medical necessity is a must before any diagnostic tests, and while some societies might offer schizophrenia screening as a part of routine care for high-risk families, some will not, which is a policy matter. The counselling and strict regulation of screenings can prevent misinformation, misinterpretation (unnecessarily alarming) and stigma.

Which population would get screened for common schizophrenia gene variants (or some novel biomarkers) matters (Ayalew 2012): an imaginative and novel statistical framework could boost the power of such screenings to a point when an application to not only high-risk individuals would become possible, spreading the schizotaxia concept even further. And if prenatal genetic screening for schizophrenia ever appear, the affluent couples without family history of schizophrenia would use it, wanting a healthy offspring, and the risk of careless test result interpretation could become a serious matter. Noninvasive prenatal diagnosis, offering more than only early detection of genetic disorders, already receives a warning for trivialization of abortion (Benn 2010), and pregnancy termination is one of the most contentious ethical and political issues.

The consensus about the level of acceptability of genetic determinism has not yet been built and the discussion transgresses the scopes of our subject, but we imagine that serendipitously discovered, high-risk pregnancies might get terminated, or, because of inadequate state programme funding, high-risk, stigmatized children rearing poorly supported from that point onward.

\section{INTERVENTIONS: WHEN AND HOW?}

Schizophrenia emerges, usually in young adulthood, after an interplay between genes and the environment, so, a full-blown disease occurs when environmental factors converge. And in certain phases of development the appropriate targets could be considered in reducing the rate of later conversion in persons at risk (Seidman \& Nordentoft 2015).

Some early interventions, especially the unspecific but beneficial measures for child development, could be done relatively harmlessly: pregnant mothers can get screening to toxoplasmosis, connected with not only higher risk for psychosis (Torrey \& Yolken 2003). Also, famine should be avoided in pregnancy, and lower birth weight, with other birth complications, prevented as well. Traumatic experiences in childhood should be reduced, and special care should be given to immigrants and refugees, since the prevalence of some psychiatric disorders can be higher in their population (Rapoport et al. 2012).

All the mentioned interventions can be done no matter of the detected schizophrenia risk, but we 
underline the importance of their implementation to families at risk, as well as giving a greater focus to relieving the burden of the disorder and the reduction in quality of life (Margetic et al. 2013) with needed social or psychiatric interventions and helping with enabling good, supportive parental care and reducing demoralization, poverty, social exclusion and other forms of suffering. There are other preventive measures that could be beneficial to the mental health of the persons no matter of the risk of conversion to psychosis, especially drug or alcohol use prevention programmes, since persons with family case of schizophrenia and use disorders have a greater rate of conversion to psychosis (Cannon et al. 2008), and also because history of substance abuse has been connected with violence in psychotic episodes (Volavka et al. 1997).

And some new experimental targets need to be mentioned: for example, supplementation of mother's diet with choline as the means of in-utero intervention is a promising, creative and personalised approach that should be additionally explored (Freedman \& Ross 2015, Ross et al. 2013). There is also a proposal for adding omega-3 fatty acids or $\mathrm{N}$-acetylcysteine (an antidote to paracetamol poisoning) to a child's at risk diet, in order to diminish the developmental anomalies caused by oxidative stress or neuroinflammation, before the onset of the disorder (Amminger et al. 2010, Berk et al. 2013, Do et al. 2015, McNamara et al. 2015, O'Donnell et al. 2014, Steullet et al. 2014) that could be considered as well. Benefits of such interventions, in terms of effective reduction of conversion rate to schizophrenia and, consequently, in terms of efficiency, shall be clear in two decades or more, after long-term studies complete, and the ethical challenge in discharging ongoing relationship with participants, considering that the efficacy would be determined much later after the participation in research, was recognised (Appelbaum 2015).

Most of the targets mentioned before could be applied without harming the persons identified at risk, and very early as well, before any symptoms occur, and therefore, with relatively easier ethical dilemmas. A few studies, tracing impairments in families at risk, from perinatal period onward, with various early interventions as a goal, are ongoing (Seidman \& Nordetoft 2015), and some others trials have already shown some benefits of giving low-dose risperidone to adult, firstdegree relatives with impairments in several measures of clinical, neurocognitive and social function: up to 2 milligrams of risperidone a day could attenuate some schizophrenia-related cognitive and social difficulties in adults with schizotaxia (Stone et al. 2015). And in another, seven year long study, a marked improvement in cognitive, social, and vocational functioning of seven relatives of patients with schizophrenia has been brought about by continuous use of 1-2 mg risperidone a day (Rybakowski et al. 2007). But translating those findings to recommendations for low-dose antipsychotic use from the childhood, when first cognitive problems in families with schizophrenia occur (Seidman et al.
2013.) would be premature, since relatively few published data on adverse events of risperidone or other antipsychotics in that class in adolescent patients are available (Pringsheim et al. 2011). And before the grasp on the subject gets possible, another ethical issue should be tackled: psychiatric research in minors, with intervention containing more than minimal risk of harm. Such ethical challenge is addressed in one study of prodromes as beneficial for participants to justify the risk, with benefit at least as favourable as the alternative (watch and wait), and by providing two informed consents, one from parent and one from an adolescent (McGlashan et al. 2001). However, would such criteria stand in targeting cognitive impairments in 7-year-olds pharmacologically? Considering the now necessary rate of false-positives - ever greater in every step prior to apparent psychosis - we could say the risk is not appropriate for the level of benefit in the anecdotal studies with currently available antipsychotic drugs.

Recent reports on cognitive remediation therapy in patients with schizophrenia find that younger patients with less cognitive deficit benefit the most (Keshavan et al. 2014, Kontis et al. 2013), so maybe this option could be given to minors at risk when first sign of deficit is detected. If the intervention in such early phase shows great efficacy, exposing high-risk family members to brain neuroimaging in childhood could provide a valuable insight in neurodevelopment (Rapoport 2012) and the opportunity to prevent the progression.

\section{PRODROMES: 'LAST MINUTE' IS IMPORTANT}

A prodromal period of one to three years precedes schizophrenia, when a behavioural change and functional deterioration, as well as various psychotic symptoms might occur. Up to $40 \%$ of persons with prodromes referred to clinical services gets schizophrenia within 12 months, so a delay or prevention of conversion to psychosis is rather important (Cornblatt et al. 2012; Haroun et al. 2006, Stafford et al. 2013). Some researchers find that people with prodromes are already ill and do not only need preventive intervention but also treatment (Ruhrmann et al. 2010.), although the diagnosis cannot be given yet; but others, in contrast, propose that favourable environment might even result with some benefits in, for example, creative life areas of a highrisk person (Ayalew 2012) and wonder whether such benefits could be lost if they get medicated or stressed about the risks. Considering the findings that more than 50 percent of detected persons will not convert to psychosis, some propose that monitoring of mental state, supportive therapy, and attention to current practical needs would be sufficient. Since it can be selflimiting in the majority of cases, regular assessment of mental state to detect first episode of psychosis is indicated, in order to provide treatment - from mild psychological support and family stress reduction (Yung 
et al. 2012) to pharmacotherapy and hospital stay, if necessary - so that the worse-case scenarios, violence and suicide, get prevented (Large \& Nielssen 2011, Vilibić et al. 2015).

\section{WHO CARES?}

The complexity of practical and ethical challenges surrounding current state of research on possible primary prevention of schizophrenia, with unsubstantial data on many critical points, cannot be solved without a collaborative work of many experts. Some common pathways are obvious, starting in the psychiatric office after an adult with schizophrenia is provided with initial care and adult family members with the information about the risks for them and their offspring, but getting the support from that point onward could get complicated. Much of the work in stigma reducing should be done immediately afterwards by pediatricians, school or family physicians, social care providers and various therapists, which means not only health care system, but social services and schools would be involved, if necessary. The capacities for such approach should yet be built.

Whoever gets involved, the possibility of schizophrenia development in at-risk child's later life should be explained properly and competently. It could introduce additional stress and tension in entire family, so the information, reassurance or even referrals should be given as gently as possible, in order to reduce discrimination. Offered help should introduce as less harm as possible, especially in the earliest phases.

\section{CONCLUSION}

Lucy van Pelt told Charlie Brown: "In all of mankind's history, there has never been more damage done than by people who 'thought they were doing the right thing'." (Shultz 1971)

Our knowledge about the nature and the spectrum of schizophrenia development is growing, and the possibilities of the interventions are greater than ever. That raises the need to address possible clinical, legal and moral issues in this field. Targeting the vulnerable persons without clearly indicated clinical treatment needs the assessment of risks and benefits. It will be a great challenge to construct a valid screening procedure for appropriate risk detection without harming a number of false-positive young people with stigma and adverse effects of medication, or wasting a great amount of public resources on a large-scale therapeutic interventions with limited effectiveness. However, when such screening procedure becomes available to persons with relatives suffering schizophrenia, we propose revisiting appropriate proven targets to prevent or delay the onset of a full-blown disorder, but with great focus on patient welfare, autonomy, justice and stigma reduction. The broadest public, and especially the experts that will build the safety-net for the at-risk individuals, should get best possible appropriate education about the schizophrenia in order to stigmatize less and help more: it is a bare minimum that families that suffer deserve.

Psychopharmacological interventions should be reserved for cases with very high certainty that patients' well-being is at stake, no matter in which point of the dimension does a person at risk reside. Low-risk interventions are more appropriate as the early targets in the broadest risk groups, but their efficacy should be explored. We underline the importance of the addiction prevention in persons at risk for schizophrenia, in order to avoid the progression to psychosis and possible violent outbursts.

\section{Acknowledgements: None.}

Conflict of interest: None to declare.

\section{Contribution of individual authors:}

Study conception and design: Kresimir Radic, Marko Curkovic \& Maja Zivkovic;

Aquisition of data, or analysis and interpretation of data: Kresimir Radic, Marko Curkovic, Dario Bagaric, Maja Vilibic, Andrea Tomic \& Maja Zivkovic;

Drafting the article or revising it critically for important intellectual content: Kresimir Radic, Marko Curkovic, Dario Bagaric, Maja Vilibic, Andrea Tomic \& Maja Zivkovic;

Final approval of the version to be published: Kresimir Radic, Marko Curkovic, Dario Bagaric, Maja Vilibic, Andrea Tomic \& Maja Zivkovic.

\section{References}

1. Amminger GP, Schäfer MR, Papageorgiou K, Klier CM, Cotton SM, Harrigan SM et al.: Long-chain omega-3 fatty acids for indicated prevention of psychotic disorders: a randomized, placebo-controlled trial. Arch Gen Psychiatry 2010; 67:146-54. doi: 10.1038/mp.2012.37

2. Appelbaum PS: Ethical Challenges in the Primary Prevention of Schizophrenia. Schizophr Bull 2015; 41:773-5. doi: $10.1038 / \mathrm{mp} .2012 .37$

3. Ayalew M, Le-Niculescu H, Levey DF, Jain N, Changala $B$, Patel SD et al.: Convergent functional genomics of schizophrenia: from comprehensive understanding to genetic risk prediction. Molecular Psychiatry 2012; 17:887-905. doi: 10.1038/mp.2012.37

4. Benn PA \& Chapman AR: Ethical challenges in providing noninvasive prenatal diagnosis. Curr Opin Obstet Gynecol 2010; 22:128-34. doi: 10.1097/GCO.0b013e3283372352

5. Berk M, Malhi GS, Gray LJ \& Dean OM: The promise of $\mathrm{N}$-acetylcysteine in neuropsychiatry. Trends Pharmacol Sci 2013; 34:167-77. doi: 10.1016/j.tips.2013.01.001

6. Cannon TD, Cadenhead K, Cornblatt B, Woods SW, Addington J, Walker E et al.: Prediction of Psychosis in Youth at High Clinical Risk: A Multisite Longitudinal Study in North America. Arch Gen Psychiatry 2008; 65:28-37. doi: 10.1001/archgenpsychiatry.2007.3 
7. Committee on Ethics \& Committee on Genetics, American College of Obstetricians and Gynecologists: ACOG Committee Opinion No. 410: Ethical issues in genetic testing. Obstet Gynecol 2008; 111:1495-502. doi: 10.1097/AOG.0b013e31817d252f

8. Cornblatt BA, Carrión RE, Addington J, Seidman L, Walker EF, Cannon TD et al.: Risk factors for psychosis: impaired social and role functioning. Schizophr Bull 2012; 38:1247-57. doi: 10.1093/schbul/sbr136.

9. Cuijpers $P$, van Straten A, Smit F, Mihalopoulos $C \&$ Beekman A: Preventing the Onset of Depressive Disorders: A Meta-Analytic Review of Psychological Interventions. Am J Psychiatry 2008; 165:1272-80. doi: 10.1176/appi.ajp.2008.07091422

10. Do KQ, Cuenod $M$ \& Hensch TK: Targeting Oxidative Stress and Aberrant Critical Period Plasticity in the Developmental Trajectory to Schizophrenia. Schizophr Bull 2015; 41:835-46. doi: 10.1093/schbul/sbv065

11. Erlenmeyer-Kimling L, Squires-Wheeler E, Adamo UH, Bassett AS, Cornblatt BA, Kestenbaum CJ et al.: The New York High-Risk Project. Psychoses and cluster A personality disorders in offspring of schizophrenic parents at 23 years of follow-up. Arch Gen Psychiatry 1995; 52:857-65

12. Freedman $R$ \& Ross $R G$ : Prenatal choline and the development of schizophrenia. Shanghai Arch Psychiatry 2015; 27:90-102. doi:10.11919/j.issn.1002-0829.215006

13. Fusar-Poli P, Bonoldi I, Yung AR, Borgwardt S, Kempton $M J$, Valmaggia $L$ et al.: Predicting psychosis: metaanalysis of transition outcomes in persons at high clinical risk. Arch Gen Psychiatry 2012; 69:220-29. doi: 10.1001/archgenpsychiatry.2011.1472

14. Haller CS, Padmanabhan JL, Lizano P, Torous J \& Keshavan $M$ : Recent advances in understanding schizophrenia. F1000Prime Reports 2014; 6:57. doi:10.12703/P6-57

15. Haroun N, Dunn L, Haroun A \& Cadenhead KS: Risk and Protection in Prodromal Schizophrenia: Ethical Implications for Clinical Practice and Future Research. Schizophr Bull 2006; 32:166-78

16. Insel TR: Rethinking Schizophrenia. Nature 2010; 468:187-93. doi:10.1038/nature09552

17. Jablensky A: The diagnostic concept of schizophrenia: its history, evolution, and future prospects. Dialogues Clin Neurosci 2010; 12:271-87

18. Jakovljevic M: Shizofrenija u teoriji i praksi: Etiopatogeneza i klinička praksa. Pro Mente - Zagreb, Zagreb, 2011

19. Kahn RS \& Keefe RS: Schizophrenia is a cognitive illness: time for a change in focus. JAMA Psychiatry 2013, 70:1107-12. doi: 10.1001/jamapsychiatry.2013.155

20. Kendler $K \&$ \&ardner $C$ : The risk for psychiatric disorders in relatives of schizophrenic and control probands: A comparison of three independent studies. Psychol Med 1997; 27:411-9

21. Keshavan MS, Kulkarni S, Bhojraj T, Francis A, Diwadkar $V$, Montrose DM et al.: Premorbid cognitive deficits in young relatives of schizophrenia patients. Front Hum Neurosci 2010, 3:62. doi: 10.3389/neuro.09.062.2009

22. Keshavan MS, Vinogradov S, Rumsey J, Sherrill $J$ \& Wagner A: Cognitive Training in Mental Disorders: Update and Future Directions. Am J Psychiatry 2014; 171:510-22. doi: 10.1176/appi.ajp.2013.13081075

23. Kontis D, Huddy V, Reeder C, Landau $S$ \& Wykes $T$ : Effects of age and cognitive reserve on cognitive remediation therapy outcome in patients with schizophrenia. Am J Geriatr Psychiatry 2013; 21:218-30
24. Large MM, Nielssen O: Violence in first-episode psychosis: A systematic review and meta-analysis. Schizophr Res 2011; 125:209-20. doi: 10.1016/j.schres.2010.11.026

25. Margetic BA, Jakovljevic M, Furjan Z, Margetić B \& Marsanic VB: Quality of life of key caregivers of schizophrenia patients and association with kinship. Cent Eur J Public Health 2013; 21:220-3

26. Maric NP \& Svrakic DM: Why schizophrenia genetics needs epigenetics: a review. Psychiatr Danub 2012; 24:2-18

27. McGlashan TH, Miller TJ \& Woods SW: Pre-onset detection and intervention research in schizophrenia psychoses: current estimates of benefit and risk. Schizophr Bull 2001; 27:563-70

28. Meehl PE: Schizotaxia revisited. Arch Gen Psychiatry 1989; 46:935-44

29. Mueser KT \& McGurk SR: Schizophrenia. Lancet 2004; 363:2063-72

30. Nelson MT, Seal ML, Pantelis C\& Phillips LJ: Evidence of a dimensional relationship between schizotypy and schizophrenia: a systematic review. Neurosci Biobehav Rev 2013; 37: 317-27. doi: 10.1016/j.neubiorev.2013.01.004

31. Niemi LT, Suvisaari JM, Haukka JK, Wrede G \& Lönnqvist JK: Cumulative incidence of mental disorders among offspring of mothers with psychotic disorder. Results from the Helsinki High-Risk Study. Br J Psychiatry 2004; 185:11-7

32. O'Donnell P, Do KQ \& Arango C: Oxidative/Nitrosative Stress in Psychiatric Disorders: Are We There Yet? Schizophr Bull 2014; 40:960-2. doi:

10.1093/schbul/sbu048

33. Onstad S, Skre I, Edvardsen J, Torgersen S \& Kringlen E: Mental disorders in first-degree relatives of schizophrenics. Acta Psychiatr Scand 1991; 83:463-7

34. Parnas J, Cannon TD, Jacobsen B, Schulsinger H, Schulsinger $F \&$ Mednick SA: Lifetime DSM-III-R diagnostic outcomes in the offspring of schizophrenic mothers. Results from the Copenhagen High-Risk Study. Arch Gen Psychiatry 1993; 50:707-14

35. Pringsheim T, Lam D, Ching D \& Patten S: Metabolic and neurological complications of second-generation antipsychotic use in children: a systematic review and metaanalysis of randomized controlled trials. Drug Saf 2011; 34:651-68. doi: 10.2165/11592020-000000000-00000

36. Rapoport JL, Giedd JN \& Gogtay N: Neurodevelopmental model of schizophrenia: update 2012. Mol Psychiatry 2012; 17:1228-38. doi: 10.1038/mp.2012.23

37. Ross RG, Hunter SK, McCarthy L, Beuler J, Hutchison $A K$, Wagner $B D$ et al: Perinatal choline effects on neonatal pathophysiology related to later schizophrenia risk. Am J Psychiatry 2013; 170:290-8. doi: 10.1176/appi.ajp.2012.12070940

38. Ruhrmann S, Schultze-Lutter F, Bechdolf A \& Klosterkötter J: Intervention in at-risk states for developing psychosis. Eur Arch Psychiatry Clin Neurosci 2010; 260:S90-4. doi: 10.1007/s00406-010-0139-5

39. Rybakowski JK, Drozdz W, Borkowska A: Long-term administration of the low-dose risperidone in schizotaxia subjects. Hum Psychopharmacol 2007; 22:407-12

40. Seidman LJ, Cherkerzian S, Goldstein JM, Agnew-Blais J, Tsuang MT \& Buka SL: Neuropsychological performance and family history in children at age 7 who develop adult schizophrenia or bipolar psychosis in the New England Family Studies. Psychol Med 2013; 43:119-31. doi: 10.1017/S0033291712000773 
41. Seidman LJ, Nordentoft M: New Targets for Prevention of Schizophrenia: Is It Time for Interventions in the Premorbid Phase? Schizophr Bull 2015; 41:795-800. doi: 10.1093/schbul/sbv050

42. Schultze-Lutter F, Ruhrmann S, Berning J, Maier $W$ \& Klosterkötter J: Basic Symptoms and Ultrahigh Risk Criteria: Symptom Development in the Initial Prodromal State. Schizophr Bul 2010; 36:182-91. doi:10.1093/schbul/sbn072

43. Schultze-Lutter F, Schimmelmann BG \& Ruhrmann S: The near Babylonian speech confusion in early detection of psychosis. Schizophr Bull 2011; 37:653-5. doi: 10.1093/schbul/sbr039

44. Shulz CM: The Complete Peanuts 1971-1972. Fantagraphics, Seattle 2009

45. Stafford MR, Jackson H, Mayo-Wilson E, Morrison AP \& Kendall T: Early interventions to prevent psychosis: systematic review and meta-analysis. BMJ. 2013; 346:f185. doi: 10.1136/bmj.f185

46. Stone WS, Hsi X, Giuliano AJ, Tan L, Zhu S, Li L et al: Are neurocognitive, clinical and social dysfunctions in schizotaxia reversible pharmacologically? Results from the Changsha study. Asian J Psychiatr 2012; 5:73-82. doi:10.1016/j.ajp.2011.12.001

47. Steullet P, Cabungcal JH, Monin A, Dwir D, O'Donnell $P$, Cuenod $M$ et al: Redox dysregulation, neuroinflammation, and NMDA receptor hypofunction: A "central hub" in schizophrenia pathophysiology? Schizophr Res 2014 [IN PRESS, (26.10.2015.) TO UPDATE
REFERENCE IN PROOF] doi: 10.1016/j.schres.2014.06.021

48. Torrey EF \& Yolken RH: Toxoplasma gondii and schizophrenia. Emerging Infectious Diseases 2003; 9:1375-80. doi:10.3201/eid0911.030143

49. Tsuang MT, Stone WS, Tarbox SI \& Faraone SV: Treatment of nonpsychotic relatives of patients with schizophrenia: Six case studies. Am J Med Genet 2002; 114:943-948. doi: 10.1002/ajmg.10363

50. Vilibić M, Bagarić D, Kolarić B, Radic K, Curkovic $M$ \& Zivkovic M: Suicide as the first manifestation of firstepisode psychosis in 21-year-old man: a case report. Psychiatr Danub 2015; 27:285-7

51. Vos T, Barber RM, Bell B, Bertozzi-Villa A, Biryukov S, Bolliger I et al.: Global, regional, and national incidence, prevalence, and years lived with disability for 301 acute and chronic diseases and injuries in 188 countries, 19902013: a systematic analysis for the Global Burden of Disease Study 2013. Lancet 2015; 386:743-800. doi: 10.1016/S0140-6736(15)60692-4

52. Volavka J, Laska E, Baker S, Meisner M, Czobor P \& Krivelevich I: History of violent behaviour and schizophrenia in different cultures. Analyses based on the WHO study on Determinants of Outcome of Severe Mental Disorders. Br J Psychiatry 1997; 171:9-14

53. Yung AR, Woods SW, Ruhrmann S, Addington J, SchultzeLutter F, Cornblatt BA, et al.: Whither the Attenuated Psychosis Syndrome? Schizophr Bull 2012; 38:1130-4. doi: $10.1093 / \mathrm{schbul} / \mathrm{sbs} 108$

Correspondence:

Krešimir Radić, MD

University Psychiatric Hospital Vrapče

Bolnička cesta 32, 10000 Zagreb, Croatia

E-mail: kresimir.radic@bolnica-vrapce.hr 